\title{
Sources of Marine Pollution on Nigerian Coastal Resources: An Overview
}

\author{
J. A. Akankali1' E. I. Elenwo ${ }^{2}$ \\ ${ }^{1}$ Department of Fisheries, Faculty of Agriculture, University of Port Harcourt, Choba, Nigeria \\ ${ }^{2}$ Department of Geography and Environmental Management, Faculty of Social Science, University of Port \\ Harcourt, Choba, Nigeria \\ Email: iyke2 elenwo@yahoo.com
}

Received 13 February 2015; accepted 2 April 2015; published 8 April 2015

Copyright (C) 2015 by authors and Scientific Research Publishing Inc.

This work is licensed under the Creative Commons Attribution International License (CC BY).

http://creativecommons.org/licenses/by/4.0/

(c) $\underset{\mathrm{EY}}{\mathrm{B}}$ Open Access

\section{Abstract}

Little is known about the full impacts of marine litter, especially in the open ocean where there is almost no information. The ocean is a vital source of nourishment, especially to the people in the world's poorest nations. Many depend on fish for their source of protein; fisheries and aquaculture support the livelihoods of about 540 million people directly or indirectly [1]. Overfishing, loss of biodiversity and possible extinction of species put stress on these limited resources. Some beaches are already closed to public because the water is unsuitable for bathing and beach is covered with litters of plastics, discharge of sewage, agricultural run-off, and discharge of nutrients and pesticides accounts for approximately $80 \%$ of marine pollution [2]. The scenario is not different in Nigeria as there are reported cases of major industries such as fertilizer and petrochemical and oil producing companies that have polluted the marine environment in recent times. Therefore, this paper advocates by way of education and enlightenment to the populace the myriad of problems associated with marine pollution in the Nigerian coastal waters. Some suggested solution includes education, laws and collaboration amongst organization to create a sustainable marine ecosystem in Nigeria.

\section{Keywords}

Sources, Marine Pollution, Coastal Resources

\section{Introduction}

The increase in production of crude oil and gas in Nigeria, and its progressive yield of foreign exchange for the country for the rapid expansion in industrialization, followed by increased urbanization has left the environment 
especially the coastal environment with pollutants at concentration capable of causing harm to both terrestrial and aquatic life forms. This paper examines the sources of major pollutants into the Nigerian coastal waters on the marine biota and the water quality. A wide range of criteria was adopted in explaining the various types of pollutants impacting the marine environment, their sources (land based sources, household sources, marine litters/garbage, operational sources such as fishing vessels, boats/ships and other at-sea activities), that introduce pollutants into the waters etc.

The term pollution generally refers to the alteration of the natural physico-chemical characteristics of an entity, medium or matter as a result of the presence of substances or compounds that are not supposed to be present in it or that are present in quantities and qualities that would alter the natural balance of the particular entity, medium or matter. Consequently, we can classify pollution in terms of where or medium of occurrence, such as water or aquatic pollution (marine, brackish or fresh water pollution), atmospheric pollution and soil/land pollution. Furthermore, pollution can be classified in terms of the type of the causative matter or compound, such as Chemical pollution, Noise pollution, air pollution, Agrochemical pollution, and Industrial and Domestic effluent pollution to mention but a few [1].

The generally accepted definition of the term marine pollution as drawn up by congress of working group of the United States Marine (and estuarine pollution) is the "introduction by man directly or indirectly of substances or energy into the marine (estuarine) environment resulting in such deleterious effects as harm to living resources, hazard to human health, hindrance to marine activities including fishing, impairment of quality for the use of sea water and reduction of amenities" [2]. Although these delineations exist, their precise boundary in reality overlaps over a wide area, especially from the fresh water through the brackish water to the saline or brine water. For the purpose of this review, the term marine pollution is meant to encapsulate the brackish water, saline or brine aquatic environment.

\section{Nature and Extent of Coastal Environment}

The coastal area is low lying with heights of not more than $3.0 \mathrm{~m}$ above sea level and are generally covered by fresh water swamp, mangrove swamp, lagoon mashes, tidal channels, beach ridges and sand bars [3]. The major distinguishing parameter that separates the brackish water from the fresh water environment is their different salinity ranges. The salinity of any water body is simply a measure of the sodium chloride content of that water body and it is measured in parts per thousand (ppt). The salinity ranges of the fresh water, brackish water (estuarine mainly) and the fresh water are shown in Table 1 [4].

The coastal environment generally refers to any piece of land next to, bothering or adjourning the sea shore. The extent of the coastal environment also varies immensely, depending on the object of the context within which it is being defined. Sometimes, it simply means the narrow linear corridor of shore line separating the continental shelf from the oceanic land mass. At other times it may be considered to extend both largely inwards, towards the continental shelf and outwards, farther away from the shore line towards the terrestrial land mass [4]. For the purposes of evaluating marine pollution sources and its effects on the coastal environment, the latter description is considered more suitable. Consequently, the coastal environment can be said to transcend the shore line up to the exclusive economic zone seaward and across the estuarine and intertidal zones to the lower reaches of the fresh water tributaries, sandy beaches and sometimes even arid continental land masses landwards where such bounds the world Seas and Oceans [4]. Figure 1 is showing the Nigerian coastal environment and is used to illustrate the possible extent of coastal environment. The nature of coastal environments which is often a complex mix of the different ecologies of both the fresh and salt water habitats makes it naturally to be one of the richest environments in terms of biodiversity resources and mineral deposits. [5] reported that the mangrove swamp of the Niger Delta (a coastal environment) is a highly productive area of the region in terms of fisheries resources. For example a lot of brackish fin fish and shell fishes abound in this area; examples include the crabs,

Table 1. Classification of water bodies based on salinity ranges.

\begin{tabular}{ccc}
\hline & Water salinity based on dissolved salts & \\
\hline Fresh water & Brackish water & Saline water \\
\hline$<0.05 \mathrm{ppt} \%$ & $0.05 \mathrm{ppt} \%-3 \mathrm{ppt} \%$ & $3 \mathrm{ppt} \%-5 \mathrm{ppt} \%$ \\
\hline
\end{tabular}

Source: Adapted from [4]. 


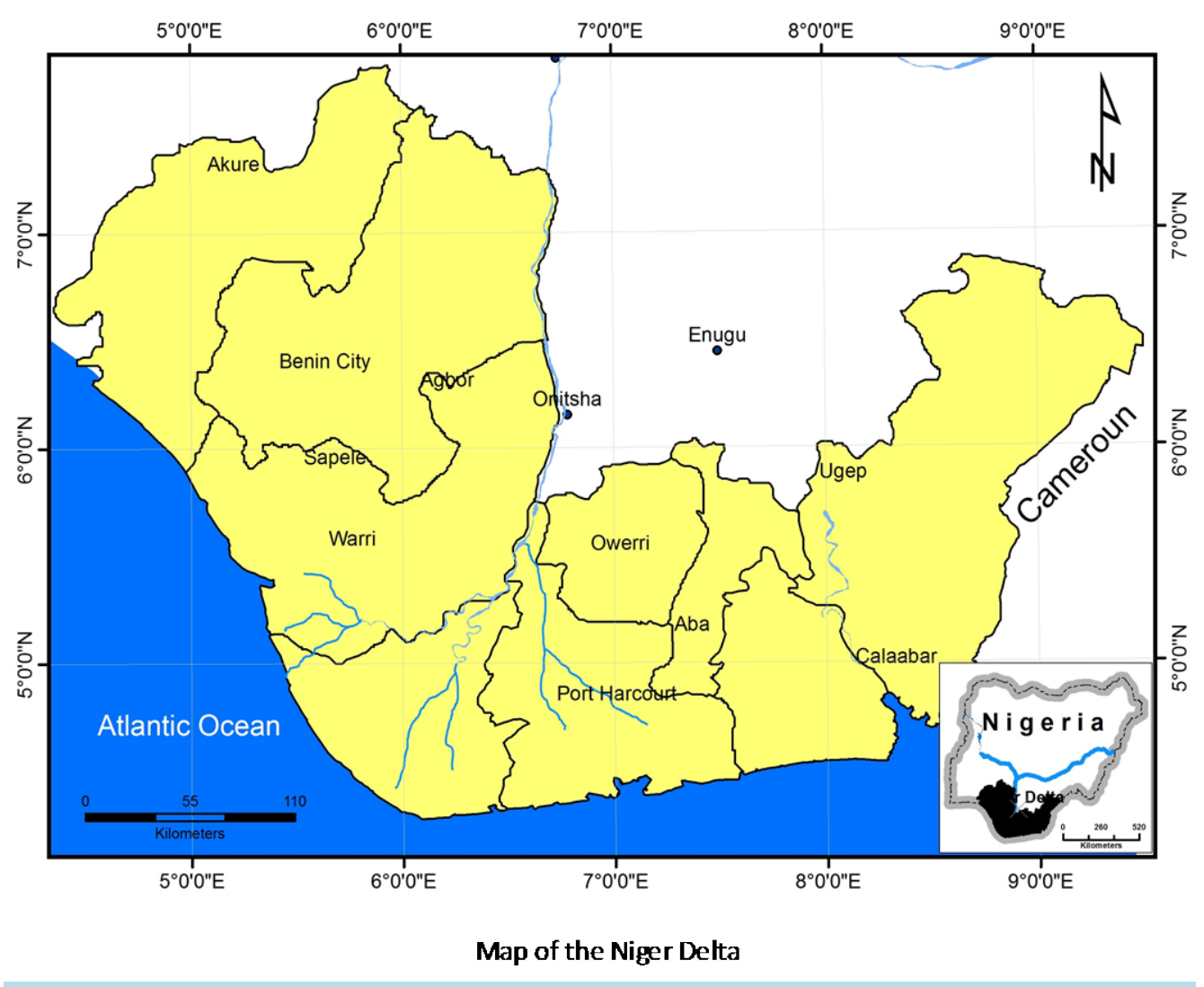

Figure 1. Map of Nigerian coastal areas [7].

oysters, clams, periwinkles etc. These fisheries resources support a wide array of fishers and thus serve as very important means of livelihood for the practitioners. The national data of United States corroborates this assertion. "Nationally, almost 35\% of all 'threatened' and 'endangered' species are either located in or dependent on wetland habitats and $90 \%$ of the species of commercially important fish and shellfish either pass their entire lives in estuarine habitats or require estuaries as nursery grounds” [6].

\section{Types of Pollutants}

Pollutant types based on the nature of the polluting substance is often categorized fundamentally into Physical, chemical, biological and radioactive pollutants [8]. However, there is a further classification, based on the on the environment of occurrence, source of the pollutant or even mode of impact. This latter form of classification could be highly subjective, depending on what the classifier perceptions and objectives may be. However, it is entirely well defined and the importance of the classification is easily understood from the context of such classification. Some types of water pollutants based on both the former and latter basis of classification are discussed as follows:

Energy pollutants: There are various forms of energy sources available to man either naturally or enhanced and exploited by man as forms of artificial energy. Some of these forms of energy include Noise, Heat, Nuclear, Vibration and solar (Ultraviolet and other forms of radiation). These energy forms are utilizable by man and applied in various forms to drive the various forms of human socioeconomic activities with the exception of noise. Incidentally, a significant portion of these energy sources end up in the aquatic environment as what could be termed as thermal energy residues that eventually constitutes thermal pollutants. Thermal pollution occurs mainly through the creation of a phenomenon known as thermal plume (Figure 2). This creates thermal shock for the aquatic organisms that can lead to either death or other physiologic problems [1].

Organic or Biological pollutants: Life processes of organisms leads to the generation of a class of pollutants that inevitably impacts the aquatic environment. Some of these include urine, feaces and various other products of decay process of organics from living or dead organisms. Incidentally, geometric increases in human popula- 




Figure 2. Illustration of a hypothetical thermal plume condition in an aquatic environment from an industrial/point source [1].

tion and the need to keep up with providing food for the astronomically rising global population has led to corresponding increases in crop and animal productions. This increases the amount of biological pollutants that eventually get into our aquatic environment. Especially in urban areas and in highly industrialized cities that have water bodies, biological pollutants have rendered most municipal water bodies highly toxic. In Lagos Nigeria for example, most of the Lagos lagoon has become so badly polluted from the indiscriminate dumping of untreated human waste and open defecation and urination into the waters among other pollutants. The water body is perpetually black in colour, with stench like strong ammonia $\left(\mathrm{NH}_{3}\right)$ odour. This is an indication of heavily polluted waters, mostly from biological pollutants. Aquatic life in such water is reduced to the barest minimum, as the primary producers are completely wiped out [1]. Human wastes in particular generally cause serious problems to the marine environment. The disposal of untreated human waste is one of the largest contributors to the pollution of the marine environment. There is numerous health problems associated with it. Even in places where there are septic tanks and soak away pits they tend to overflow and in many of the coastal villages in rural settings due to lack of proper toilet facilities especially in developing nations like Nigeria. Human waste gets discharged into the sea or coastal waters either directly or through streams, rivers and storm drainages [1]. A perfect example is depicted in Plate 1.

Furthermore, as human populations grows more and more categories of pollutants impacts both the fresh and brackish waters. One of the most common pollution in this category is the organic pollutant caused by oxygen-demanding wastes as domestic sewage, wood fiber from pulp and paper mills, effluent from food processing plants, and run-off from agricultural areas (especially hay, dairy, and cattle farms). Dissolved oxygen is consumed either through chemical oxidation of these substances or through the respiratory processes of biological decomposition. Decomposition of materials is a normal process in all aquatic ecosystems and is a function of decomposers such as bacteria and fungi. These organisms metabolize the organic matter as an energy and nutrient source and utilize dissolved oxygen in the process. However, serious consequences can result if these natural mechanisms are overloaded by large influxes of organic matter. Severe oxygen depletion can result in the 


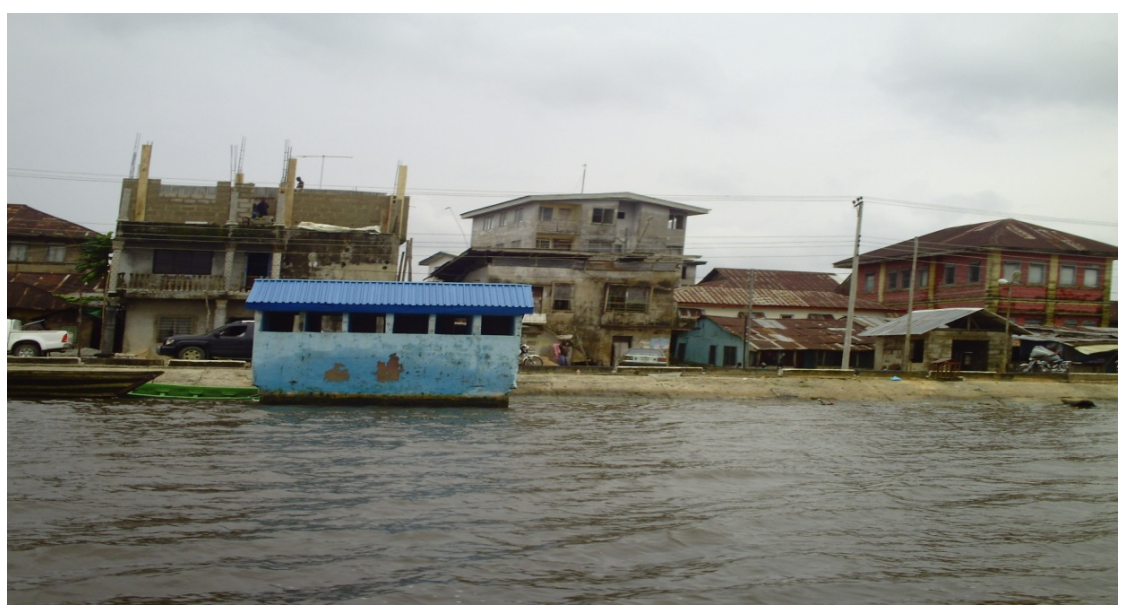

Plate 1. A typical coastal community toilet system in Niger Delta region; residents defecate directly into water body without treatment.

loss of desirable aquatic life and may produce an odorous anaerobic system [1].

Domestic pollutants: For decades, communities, settlements and municipalities have utilized water courses for domestic chores, transportation and as the sink for waste. However sewage depletes the much needed dissolved oxygen and contains high concentration of bacterial and viral life forms, some of which could be pathogenic. In addition, effluent from municipal domestic waste treatment plants, with unknown and unusual chemicals contained in the industrial process because of trade secrets, find their way into water courses. These substances affect both the pelagic and benthic organisms and impair water quality for fish spawning and breeding, ultimately in the coastal aquatic environments.

Synthetic pollutants: Synthetic pollution involves pollutants from substances that are manufactured or synthesized by man from factories and laboratories. In other words they are artificially formulated compounds, which man utilizes as raw materials, drugs, herbicides and pesticides. Depending on the nature of the active ingredients of the synthetic pollutants, irrespective of where they are used, the residues may persist in the aquatic environment and have long lasting impacts as they may not easily be biodegradable. Pesticides constitute very good examples of synthetic pollutants. There are two major categories of synthetic products, the organo-chlorine and organo-phosphorous groups. The organo-chlorine based compounds include pesticides, pharmaceuticals and cosmetics products and plastics. For example, some pesticides like DDT are not only biologically active but stable and persist for a long time in the aquatic environment. Some organo-phosphorous based compounds are less stable and therefore of lesser persistence and impact in the aquatic environment. Although most pesticides are often used on land in agricultural estates, the aquatic environment becomes the ultimate recipients of the residues. The heavy metals in them may be in very trace quantities, but aquatic organisms such as mollusks and crustaceans are able to raise the level of concentrations through their filter feeding habits. When these substances bio-accumulate in such aquatic organisms and are consumed by man it biomagnifies the adverse health hazards of the pollutants. It has been reported that over $90 \%$ of the detergents which are the commonest in use today are biodegradable; many new pesticides such as the organo-phosphorous group break down readily in water, although not necessarily to simple inorganic salts [8]. Even where a substance is biodegradable, it does not mean that it poses no problems as the products of its breakdown may be toxic or bio-accumulated to levels at which it becomes hazardous [8].

Crude oil pollutants: Crude oil pollution, a type of chemical pollutant, deserve specific discuss as a pollutant type. This is because it has become one of the most important pollutants of the marine environment. Several factors make crude oil a top polluting substance of aquatic environment. Top among these factors include the global economic importance of crude oil as a product that drives most economies all over the world. Hence, the global demand and production of it has steadily been on the increase, thereby leading to development of numerous oil fields all over the world. Some of the major oil producing facilities around the globe are located either onshore, near shore or offshore facilities. Thirdly, most oil refining and transportation facilities are sited close to and carried on water respectively [1]. In Nigeria Niger Delta for example, the incidence of oil pollution is so rampant that it escalated wide spread socio-economic conflicts in the region, culminating in a recent trend that is 
tagged the "Niger Delta Militancy". Nigeria being a mono product economy has all its oil production taking place in the Niger Delta region. The Niger Delta region is an ecologically sensitive region that is rich in fisheries and other aquatic resources. However, oil production activities have in recent times reduced the yield of aquatic resources from these regions. The implication of this is a dislocation of the local people from their traditional occupation, which has led to violent resistance across the region [1].

Industrial pollutants: The discuss on industrial pollution as a pollutant type shall focus mainly on industrial wastewater, even though thermal heat (such as from gas flaring), radiation and other forms of industrial pollutant impacts negatively on the aquatic environment. Industrial waste water is given priority as a fundamental type of water pollutant due to its serious impact on the aquatic environment. In virtually all industrial processes, water is required as an important catalyst ingredient and as coolant etc. The excess of such waters are often released into the environment, especially into the aquatic environment with all the dissolved constituents. Most of the constituents include organics and in-organics. Undesirable Industrial wastewater may be characterized based on the nature of the industry and the projected uses of the waters of the receiving stream. These undesirable wastewater characteristics (pollutants) according to [9] include Soluble organics, Suspended solids, Heavy metals, cyanide and toxic organics, Colour and turbidity, Nitrogen and phosphorous, Refractory substances, Volatile materials oil and floating material, and aquatic toxins.

Precipitation pollutants: Liquid precipitation such as rainfall constitutes a fundamental source of marine pollutant. This is because, the processes that leads to the formation of precipitation is based on crystallization of moisture around suspended particulate matter. The particulate sources ranging from salt particles from the field, ash emitted from volcanic eruption, dust particles such as chromium, asbestos, particulates from smokestacks, crystals of salt, pollens in air or combustion by-products of coal or fossil fuel. The increasing concentration of greenhouse gases containing carbon dioxide, oxides of nitrogen and sulphure, beyond threshold levels, are responsible for acid rain which adversely affects fisheries and aquaculture, forestry and agricultural soil fertility in coastal environments [1].

Extraneous pollutants: There are pollutant types in the aquatic marine environment that are not easily recognizable and may not be easily classified. Consequently, they are termed as extraneous pollutants. When large tracts of land are plowed, the exposed soil can erode during rainstorms. Much of this runoff flows to the sea, carrying with it loose earth material that may be contaminated. In the process of sedimentation, a considerable portion of such earth material may constitute silt pollutants. Extraneous pollutants occur mainly through the non-point source of pollution, which occurs as a result of runoff. Other extraneous pollutants include minor leakages from many small sources, like septic tanks, cars, trucks, and boats, plus larger sources, such as farms, ranches, and forest areas [8]. Millions of motor vehicle engines drop small amounts of oil each day onto roads and parking lots. Much of these oil droplets make its way to the water bodies or seas. Some water pollution actually starts as air pollution, which settles into waterways and oceans. Dirt and dust from road construction during dry weather also constitutes extraneous pollutants, which impacts the aquatic marine environment. Silt from fields or construction sites can run off into waterways, harming fish and wildlife habitats [8].

\section{Sources of Water Pollution}

There are several criteria for categorizing pollution in terms of their sources. These criteria are usually based on the mode of the discharge of the pollutants into the environment, the nature of the facility from which the pollutant is emanating from, the type of processes generating the pollutants, the biological, chemical and physical properties of the pollutants etc. Some of the pollution sources based on these criteria's include:

Point source and non-point source pollution: Sources of pollution in aquatic environment could be broadly classified into "point source" and "non-point source" pollution. The point source pollution are those polluting substances emanating from specific and relatively confined cum limited spheres or channels. Examples of point sources aquatic pollution from human activities include "pipeline" discharges of polluting chemicals fluids such as crude oil into receiving waters from blow out, leaks emanating either from equipment failures, accidents or outright vandalism. Others include domestic sewage discharges or industrial waste effluents from factories or plants. Pollutants emanating from point sources are relatively easy to identify, isolate, contain and therefore manage. In contrast, non-point sources pollution resulting from human activities could be defined as those pollutants originating from relatively widespread surface area and gets discharged into the aquatic environment via extensive spheres and channels [8]. Examples of non-point sources of pollution include urban storm run offs, 
dissolved atmospheric gases and particulates such as acids from gas flaring and volcanic ash being released into the aquatic environment via precipitation. Another important example of non-point sources of pollution into the aquatic environment is the runoff from farm estates that has been treated with fertilizers, herbicides and or pesticides [8]. When such farm estates constitutes a source of water shed to adjourning water bodies, the run offs from it transports polluting substances diffusely over land into the aquatic environment. Through this type of non-point source pollution, underground water pollution occurs where the soil capillaries are porous enough to permit downward percolation of significant volumes of water arising from precipitation.

Land based pollution sources: Most ocean pollution begins on land due to the oceans and seas constituting the eventual natural sink for virtually all natural and anthropogenic activities on the globe. Land-based sources (such as agricultural run-off, discharge of nutrients and pesticides and untreated sewage including plastics) account for approximately $80 \%$ of marine pollution, globally [2]. Agricultural practices, coastal tourism, port and harbours developments, damming of rivers, urban development and construction, mining, fisheries, aquaculture, and manufacturing, among others, are all sources of marine pollution threatening coastal and marine habitats.

Agricultural pollutants deserve a special discourse under land based pollution sources, since most farmers on land carry out several practices quite ignorant of their impact on the marine environment. There are two major categories of Agricultural pollutants. These are Agrochemicals which include Herbicides, Pesticides and chemical fertilizers. The Agrochemical pollutants are very critical in consideration of pollution from agricultural enterprise. The various types of Agrochemical pollutants and their effects emanate from the use of chemical fertilizers, pesticides and herbicides. The second category is the Agro-Organic pollutants, which include green manures or organic fertilizers derivable from compost, organic domestic waste, composting and mulching processes [2]. The various Agricultural pollutants may have chemical constituents which may include heavy metals that remain as residues in the soil. These can be washed off into the aquatic environment and constitutes pollutants. Figure 3; illustrates the flow channel of Agricultural pollutants that impact aquatic organisms generally.

Household/domestic sources of pollution: Household/domestic source of water pollution constitutes a complex waste stream. It contains virtually all forms of wastes; biodegradable and non-biodegradable solid wastes including metals and plastics, liquid wastes, organics of different classes, chemical wastes etc. In most cases, these wastes are not segregated at source especially in developing countries prior to disposal. Also, indiscriminate dumping of waste into public spaces drains and in waste dumps that are devoid of the impermeable layers of a properly engineered land fill are common practices in developing countries such as Nigeria. The net consequences of this unorganized system of managing domestic waste leads to a high proportion of the waste eventually finding their way into the hydrological cycle via leachates during aquifer recharge. An emerging concern from domestic waste on marine pollution is reported by [10] "warning that household washing machines seem to be a major source of so-called 'micro plastic' pollution - bits of polyester and acrylic smaller than the head of a pin-that scientists now have detected on shorelines worldwide" (Plate 2).

Marine litters/garbage sources of pollution: There are several kinds of marine litters and garbage's being dumped into the marine environment annually in thousands of tonnages cumulatively. However, plastics appear to be the most noticeable and problematic of marine litters and garbage's for three main reasons. First, it is a floating material and once discarded into the marine environment keeps afloat almost perpetually until it is recovered. Secondly plastics are not biodegradable; hence it remains in the environment until recovered for either disposal through burning or recycling. Lastly though plastics can contribute to the reduction of our carbon footprint, appropriate disposal is often not addressed. The United Nations Environment Programme estimated in 2006 that every square mile of ocean contains 46,000 pieces of floating plastics [11].

Operational sources such as fishing vessels boats/ships: Pollution sources at sea or even on inland waters such as Rivers, lagoons, seas, harbours and estuaries constitutes sources of significant pollution to the marine environment. Some of these activities include accidental and deliberate discharges of oil during bunkering operations, operational dumping of garbage (particularly plastics, metallic and non-metallic objects). Other pollutant sources resulting from operational sources include dredge spoils (mostly routine harbours dredging) and unserviceable equipment. Dredge spoils are often rich in heavy metals (e.g. lead, copper, zinc, mercury, and cadmium), and are dumped at designated sites. An important aspect of operational sources of marine pollution that is relevant to the Nigerian coastal communities or resources is Abandoned, Lost or Otherwise Discarded fishing gears (ALDFG's). The various gears identified globally to be majorly implicated as ALDFG's include Gillnets, Pots and traps, Bottom trawl gears, Long lines and Hooks see Plate 3. These are fishing gears that are 




Figure 3. Flow channel of agricultural pollutants into the aquatic environment [1].

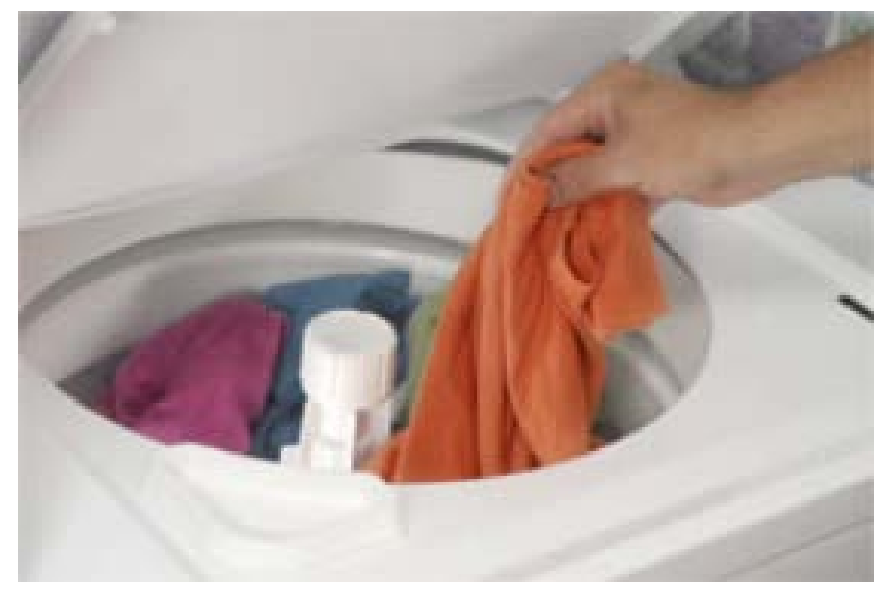

Plate 2. Home washing machines: Source of potentially harmful ocean "micro plastic pollution” [10]. 




Plate 3. A typical example of ALDFG in the aquatic environment [11].

in common use across the entire range of our coastal waters. The unfortunate point is that the problems of ALDFG's such as ghost catch, disruption of navigational activities, reduction of fishing efforts and threats to endangered or endemic species, has obviously been with us in Nigerian coastal waters with very little or no attention being paid to its adverse consequences to our coastal resources [11].

Other sea activities sources: Bunkering activities both legal and illegal of crude oil constitutes a very serious source of pollution into the marine environment. In Nigerian coastal waters, especially within the Niger Delta Region, the current unprecedented high level of illegal crude oil bunkering has led to heavy discharges of crude oil into the coastal environment of the entire coastal areas lining the gulf of Guinea [5]. Since these bunkering are largely illegal, it is extremely difficult to quantify the approximate quantity of crude oil pollution entering into the marine environment of this region. In some cases these free floating mass of hydrocarbons are ignited in a bid to destroy these illegal bunkering and crude oil refining activities. These lead to total wiping out of aquatic organisms especially pelagic species [5]. The fate of spilled crude oil into the aquatic environment exhibits a complex pathway; likewise the pathway of its pollution impacts, this further explained in (Figure 4 and Figure 5 respectively).

\section{Conclusion and Recommendation}

The world saw in 2010, the Gulf of Mexico deep-water oil spill that caused devastating effect on the entire marine ecosystem as well as the populations that depend on the marine areas for their livelihood. Day by day the pollution of the ocean is going on unabated causing death of birds, marine mammals, algae, fish and shell fish including hunger and malnutrition for humans. UNESCO, UNEP and other groups believes that the advocacy in support of sustainable management of the marine ecosystem is the cornerstone for the preservation of the oceans and its resources [11]. Trends over time and the effectiveness of management systems are hard to assess without good monitoring and assessment of the marine ecosystem. Therefore, this paper advocates aggressive campaign to save our seas and collaborative monitoring and assessment of the oceans as a way forward to achieving reduced pollution of the oceans.

The paper recommends the following three ways in tackling the problem of marine pollution; Education; making people aware of the problem is the first step which this paper has tried to do by highlighting some of the sources. One major problem of marine pollution is its trans boundary nature. Many rivers cross countries, while seas span whole continents. Pollution discharged by factory in one country with poor environmental standards can cause problems in neighbouring nations, even when they have tougher laws and higher standards. Environmental laws can make it tougher for people to pollute, but to be really effective they have to operate across national and international borders. This paper calls for full implementation and enforcement of the international laws governing the oceans, such as the 1982 UN Convention on the law of the Sea (signed by over 120 nations), the 1978 MARPOL International Convention for the Prevention of Pollution from Ships, the 1998 OSPAR Convention for the Protection of the Marine Environment of the North and East Atlantic and others [11]. Finally, 


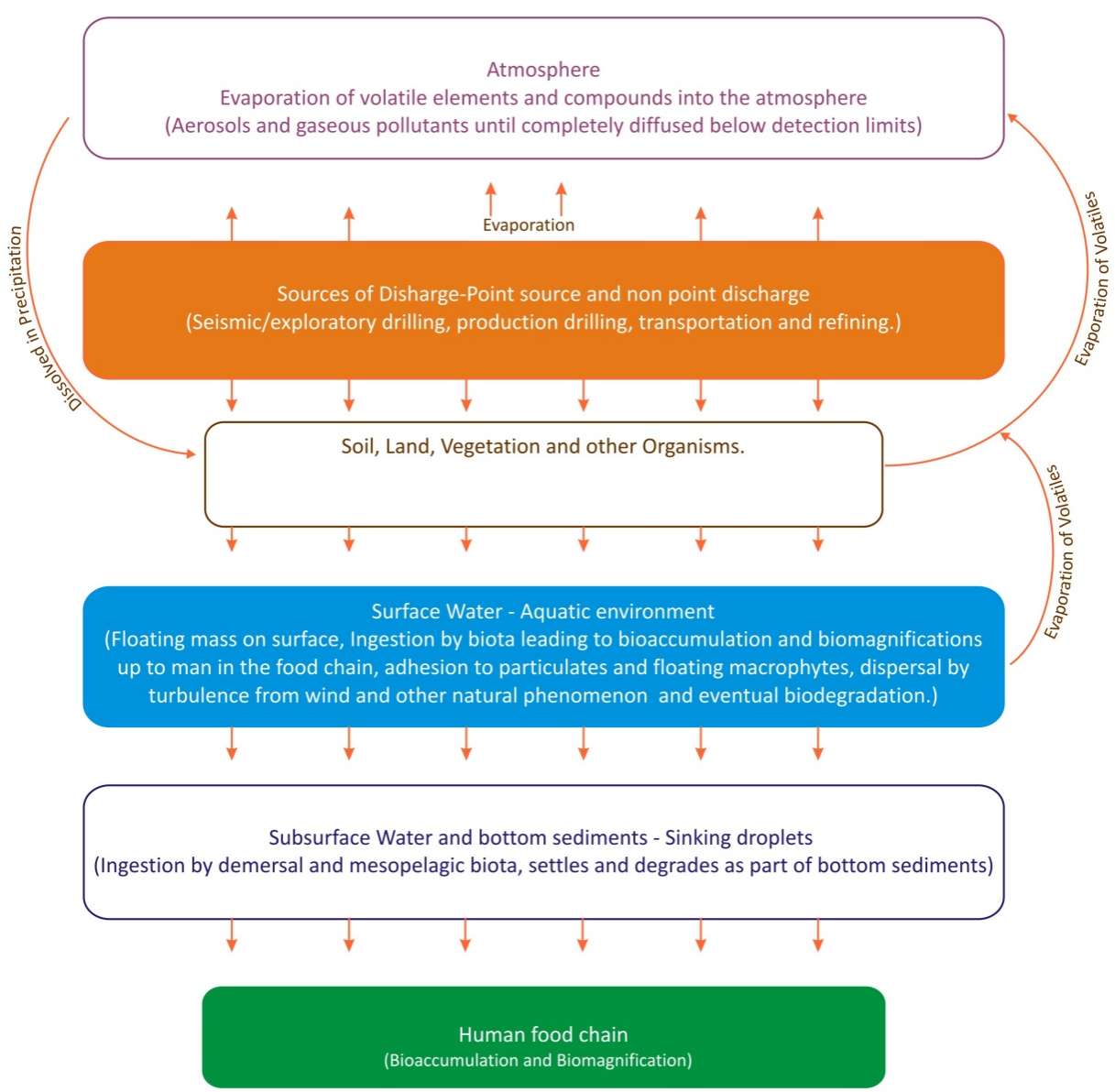

Figure 4. The pathway of crude oil in a water body is illustrated in [1].

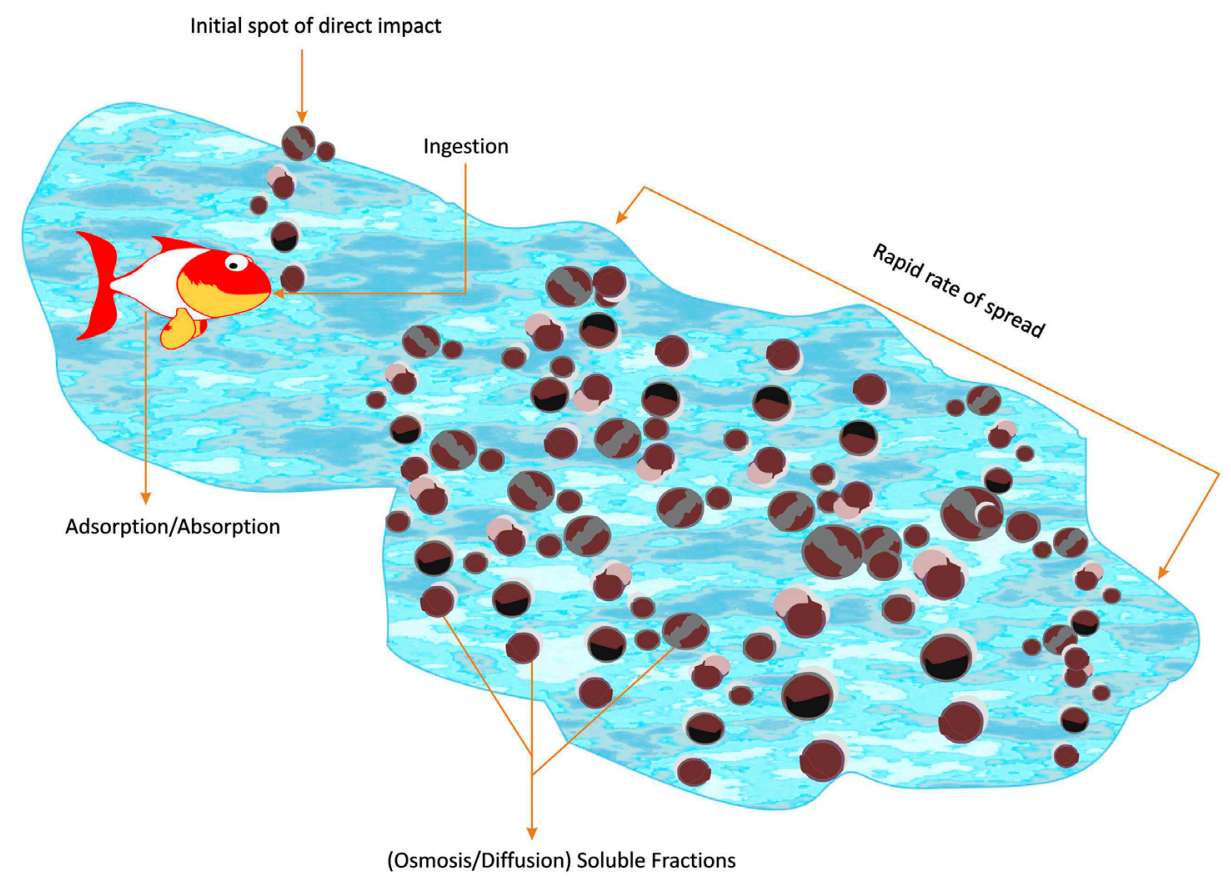

Figure 5. Pathway of spilled crude oil pollution impact in the aquatic environment [1]. 
most environmental experts agree that the best way to tackle pollution is through what is called the Polluters Pay Principle. This means that whoever causes pollution should have to pay to clean it up, one way or another. It could mean that tanker owners should have to take out insurance that covers the cost of oil spill cleanups; it could also mean that shoppers should have to pay for their plastic grocery bags, as is been done in some countries to encourage recycling and minimization of waste. It could also mean that factories that use rivers must have their water inlet pipes downstream of their effluent outflow pipes, so if they cause pollution, they are first to suffer. The whole scenario calls for concerted efforts by all for a cleaner and safer marine environment and for the world to be a better place to live.

\section{References}

[1] Akankli, J.A. and Oronsaye, J.A.O. (2012) Fundamentals of Water Pollution. Manuscript as Submitted in 2012 for Publication Assessment to Tertiary Education Fund, Abuja.

[2] Joint Experts on the Scientific Aspects of Marine Pollution (1998) The Atmospheric Input of Species to the World Oceans. Joint Experts on the Scientific Aspects of Marine Pollution, 38, 111p.

[3] Dublin-Green and Hughes, H. (1997) Global Biodiversity Assessment. In: Hey wood, A.H., Ed., Global Biodiversity Assessment, Cambridge University Press, United Kingdom.

[4] Ralph, W.T. (1993) Field Guide to Coastal Wetland Plants of the Southeastern U.S.A. University of Massachusetts Press, 328p.

[5] Akankali, J.A. and Jamabo, N.A. (2012). Effects of Flooding and Erosion on Fisheries Resources in Niger Delta, Nigeria. European Journal of Scientific Research, 90, 14-25.

[6] Sulton, J.C. and Shun, L, (1996) The Scientific Characterization of the Delware Estuary. The Delware Estuary Programme (DRBC Project No. 321; HA File No. 93.21) 200pp and Appendices.

[7] National Adaptation Strategy and Plan of action on Climate change for Nigeria (2011) NASPA-CCN, ISBN 978-0-9878656-4-9.

[8] Institute of Geo-Sciences and Space Technology (IGST) (2000) Assessment of Damage Following Oil Spill Proceedings of an International Seminar on Petroleum and Niger Delta; FMH and NNPC, PTI. Warri, Nigeria.

[9] Eckenfelder, W.W., Davis, L.F. and Englande, A.J. (2009) Industrial Water Quality: Sources and Characteristics of Industrial Waste Water. McGraw-Hill Press, New York.

[10] Browne, M.A., et al. (2011) Accumulations of Microplastic on Shorelines Worldwide: Sources and Sinks. Environmental Science and Technology, 45, 9175-9179.

[11] United Nations Environment Programme/Food and Agriculture Organization of the United Nations (2009) FAO Fisheries and Aquaculture Technical Paper No. 185 and UNEP Regional Seas Report and Studies No. 523. 